\title{
Photocatalytic Reduction of Aqueous Cr(VI) with CdS under Visible Light Irradiation: Effect of Particle Size
}

\author{
A.B. Makama ${ }^{1}$, A. Salmiaton ${ }^{*}$, Elias B. Saion ${ }^{2}$, T.S.Y. Choong ${ }^{1}$, N. Abdullah ${ }^{1}$ \\ ${ }^{1}$ Department of Chemical and Environmental Engineering, Faculty of Engineering, \\ Universiti Putra Malaysia, 43400 Serdang, Selangor Darul Ehsan, Malaysia \\ ${ }^{2}$ Department of Physics, Faculty of Science, Universiti Putra Malaysia, 43400 Serdang, \\ Selangor Darul Ehsan, Malaysia
}

Received: 14 $4^{\text {th }}$ July 2016; Revised: $11^{\text {st }}$ October 2016; Accepted: $18^{\text {th }}$ October 2016

\begin{abstract}
Stringent environmental standards have made the removal of $\mathrm{Cr}(\mathrm{VI})$ from water an important problem for environmental scientist and engineering. Heterogeneous photocatalysis using suspended photocatalyst is an interesting technique to consider for this application. In this work, the influence of particle size of suspended CdS on the photocatalytic reduction of aqueous $\mathrm{Cr}(\mathrm{VI})$ ion was investigated. The efficiency of $\mathrm{Cr}(\mathrm{VI})$ reduction was monitored through UV-visible analysis. The experimental results showed that the nanoparticle size has a dramatic effect on the adsorption and reduction of $\mathrm{Cr}(\mathrm{VI})$. As surface area increased from $44.2 \pm 0.6$ to $98.7 \pm 0.5 \mathrm{~m}^{2} / \mathrm{g}$ due to particle size reduction, the rate of $\mathrm{Cr}(\mathrm{VI})$ reduction nearly doubled in the first $20 \mathrm{~min}$ of visible light irradiation. The results evidenced the inverse relationship between the apparent reduction rate constant and the CdS particle size. Conversely, the half-life $\left(\mathrm{t}_{1 / 2}\right)$ period of the photocatalytic reduction has a direct relationship with CdS particle sizes. Copyright (C) 2017 BCREC GROUP. All rights reserved
\end{abstract}

Keywords: CdS; chromium(VI); photocatalyst; half-life; particle size

How to Cite: Makama, A.B., Salmiaton, A., Saion, E.B., Choong, T.S.Y., Abdullah, N. (2017). Photocatalytic Reduction of Aqueous $\mathrm{Cr}(\mathrm{VI})$ with CdS under Visible Light Irradiation: Effect of Particle Size. Bulletin of Chemical Reaction Engineering \& Catalysis, 12(1): $62-70$ (doi:10.9767/bcrec.12.1.593.62-70)

Permalink/DOI: http://dx.doi.org/10.9767/bcrec.12.1.593.62-70

\section{Introduction}

Photocatalytic transformation of reactants at the surface of a semiconductor is a complex multi-step process involving (a) photogeneration of conduction band electrons $\left(\mathrm{e}_{\mathrm{cb}}{ }^{-}\right)$and valence band holes $\left(\mathrm{h}_{\mathrm{vb}}{ }^{+}\right)$; (b) separation and transport of the charges to the photocatalysts surface; and (c) surface redox reaction [1]. The reductive and oxidative surface reactions involve the transfer (ejection) of electrons or

* Corresponding Author.

E-mail: mie@upm.edu.my

Telp.: +603-89466297 , Fax.: +603-86567120 holes to pre-adsorbed reactants. The rates of the surface reactions depend on the efficiency and rate of charge transfer between the photocatalyst and the substrate and on the quantity and quality of the active surface area of the photocatalyst $[2,3]$. A catalyst with large surface area is usually preferred because it usually provides large area for the adsorption of the solute, more active sites for ejection of charge carrier(s) and for the surface reactions to occur.

Literature indicates that numerous successful studies have been done to investigate the feasibility of reducing $\mathrm{Cr}(\mathrm{VI})$ to $\mathrm{Cr}$ (III) by the photocatalytic process. In general, the studies covered many aspects of photocatalysis includ- 
ing the influence of the (a) type of photocatalyst $[4,5,6,7]$, (b) irradiation intensity [8], (c) photocatalyst loading [9], (d) $\mathrm{Cr}(\mathrm{VI})$ pollutant concentration [9], (e) solution $\mathrm{pH}$ [10], and (f) addition of radical scavengers [11] on the rate of reduction of $\mathrm{Cr}(\mathrm{VI})$ to $\mathrm{Cr}(\mathrm{III})$ with the objective of optimizing the process. The findings indicate that (a) the rate of reduction increases but photoefficiency decreases with increasing irradiance, (b) the percentage of $\mathrm{Cr}(\mathrm{VI})$ photoreduced increases to a maximum and then decrease with increasing photocatalyst loading, (c) the rate of reduction increases but percentage of $\mathrm{Cr}(\mathrm{VI})$ reduced decreases with increasing $\mathrm{Cr}(\mathrm{VI})$ concentration, and (d) the rate of reduction decreases with increasing $\mathrm{pH}$. Despite these investigations on the effects of operating conditions in the photocatalytic reduction of $\mathrm{Cr}(\mathrm{VI})$ to $\mathrm{Cr}$ (III), it is not clear what changes in photocatalytic activity are expected due to the particle size of CdS photocatalyst.

In the present work, we attempted to systematically investigate the effect of particle size on the adsorption and photocatalytic reduction of $\mathrm{Cr}(\mathrm{VI})$ in aqueous medium. Towards this end, CdS nanoparticles were prepared by microwave assisted polyol precipitation method and separated into different sizes by centrifugation. The fractions were suspended in aqueous $\mathrm{Cr}$ (VI) solution to study the effect of particle size on the reduction kinetics of $\mathrm{HCrO}_{4}{ }^{2-}$ by CdS under visible-light irradiation.

\section{Materials and Method}

\subsection{Materials}

The chemicals, such as cadmium chloride $\left(\mathrm{CdCl}_{2} \cdot 2.5 \mathrm{H}_{2} \mathrm{O}\right)$, thiourea $\left(\mathrm{H}_{2} \mathrm{NCSNH}_{2}\right)$, thioacetamide and ethylene glycol $\left(\mathrm{HOCH}_{2} \mathrm{CH}_{2} \mathrm{OH}\right)$, were purchased from Merck. Polyvinyl pyrrolidone (PVP 58 000) as capping/stabilizer was purchased from Alfa Aesar (NaOH, Emsure, Germany). Sulphuric acid $\left(\mathrm{H}_{2} \mathrm{SO}_{4}, 95-98 \%\right.$, R\&M Chemicals, U.K.), ethanol $\left(\mathrm{C}_{3} \mathrm{H}_{6} \mathrm{O}\right.$, R\&M Chemicals, U.K.), potassium dichromate $\left(\mathrm{K}_{2} \mathrm{Cr}_{2} \mathrm{O}_{7}\right.$, Systerm, Malaysia) and 1,5-diphenylcarbazide $\quad\left(\mathrm{C}_{13} \mathrm{H}_{14} \mathrm{~N}_{4} \mathrm{O}, \quad \mathrm{R} \& \mathrm{M}\right.$ Chemicals, U.K.) were also used. All chemicals were of analytical grade and used as-received in the experiments without further purification.

\subsection{Synthesis of Polyvinyl Pyrrolidone (PVP) capped CdS nanoparticles}

The synthesis of CdS quantum dots (QDs) was performed in a $0-1000 \mathrm{~W}$ power microwave (MW) digester with a temperature controllable unit. PVP capped CdS quantum dots were synthesized by the microwave polyol method as previously described [12] with slight modification. In a typical synthesis, $12 \mathrm{mmol}$ of a $\mathrm{H}_{2} \mathrm{NCSNH}_{2}$ was mixed with $10 \mathrm{mmol}$ of $\mathrm{CdCl}_{2} \cdot 2.5 \mathrm{H}_{2} \mathrm{O}$ and dissolved in $100 \mathrm{~mL} 2.5$ wt.\% solution of PVP in ethylene glycol. The mixture was stirred at $550 \mathrm{rpm}$ for $1 \mathrm{~h}$ at room temperature to ensure complete dissolution of the solids. The homogeneous solution was then irradiated at medium-low power $(400 \mathrm{~W})$ in the MW digester for $10 \mathrm{~min}$ at $150{ }^{\circ} \mathrm{C}$. After about 7-8 min, the solution turned deep orange in color indicating the onset of CdS nanocrystals formation. After irradiation, the turbid CdS suspension was allowed to cool overnight in the dark. The CdS precipitate was separated by centrifugation (Kubota, Model 6500) at 5000, 10000 and $15000 \mathrm{rpm}$ for $20 \mathrm{~min}$. The precipitate was washed three (3) times with deionized water and then with pure ethanol and dried at $90{ }^{\circ} \mathrm{C}$ for $5 \mathrm{~h}$. The $\mathrm{CdS}$ fractions labelled as $\mathrm{CdS}-5$, CdS-10, and $\mathrm{CdS}-15$, respectively.

\subsection{Photocatalytic activity measurement}

Photocatalytic activities of the CdS fractions were investigated by reduction of $\mathrm{Cr}(\mathrm{VI})$ to $\mathrm{Cr}$ (III) experiments in a $400 \mathrm{~mL}$ immersion well photoreactor (model RQ400, Photochemical Reactors, UK). The schematic diagram of the photocatalytic reaction setup for the reduction of $\mathrm{Cr}(\mathrm{VI})$ is shown in Scheme 1. In a run, $0.20 \mathrm{~g}$ of the photocatalyst was added to 200 $\mathrm{mL}$ of $20 \mathrm{mg} / \mathrm{L}(68 \mu \mathrm{mol} / \mathrm{L}) \mathrm{K}_{2} \mathrm{Cr}_{2} \mathrm{O}_{7}$ solution containing $15 \%$ volume $\mathrm{CH}_{3} \mathrm{OH}$ in the reaction flask. The $\mathrm{pH}$ of the mixture was adjusted with $0.18 \mathrm{M} \mathrm{H}_{2} \mathrm{SO}_{4}$ and the flask was placed on a magnetic stirrer and stirred for $30 \mathrm{~min}$ (based on adsorption kinetic studies) in the dark to equilibrate. In the meantime, a $400 \mathrm{~W}$ halogen lamp in an immersion well that is cooled with water $(5 \mathrm{~mL} / \mathrm{s})$ was switched on for a $15-20 \mathrm{~min}$ run up time to reach maximum output. Thereafter, the immersion well with the glowing lamp was inserted into the reaction flask to start the photoreaction under continuous stirring at $500 \mathrm{rpm}$. About $3 \mathrm{~mL}$ of reaction mixture were drawn from the reactor vessel at scheduled time intervals to the maximum of $60 \mathrm{~min}$. The aliquots were immediately centrifuged at $5000 \mathrm{rpm}$ for $5 \mathrm{~min}$ to settle out the photocatalyst and collect the supernatant for analysis of the residual $\mathrm{Cr}(\mathrm{VI})$. The temporal concentrations of $\mathrm{Cr}(\mathrm{VI})$ were determined by optical absorbance measurements of the supernatants at $540 \mathrm{~nm}$ on a spectrophotometer 
(Shimadzu model UV-1800) according to the 1,5-diphenylcarbazide (DPC) procedure [13]. All aqueous solutions and dispersions were produced with 18.2 M.cm distilled de-ionized water.

\subsection{Characterization}

The X-ray diffraction (XRD) diffractogram patterns of the powdered samples were recorded using a Shimadzu X-ray diffractometer (XRD-6000) with $\mathrm{Cu}_{\mathrm{k} \alpha}$ radiation $(\lambda=0.1540$ $\mathrm{nm})$. The morphologies of the $\mathrm{CdS}$ samples were viewed using scanning electron microscopy (SEM; Hitachi S-3400N) and energy filtering transmission electron microscope (Leo 912AB EFTEM).

Ultraviolet-Visible (UV-VIS) diffuse reflectance spectra of all samples were obtained on a Shimadzu UV-Vis-NIR Spectrophotometer (model UV-3600, Japan) equipped with a Ba$\mathrm{SO}_{4}$ coated integrating sphere. Samples were lightly ground using an agate mortar and pestle to form loose agglomerates of about $0.1 \mathrm{~mm}$ in size prior to optical measurements. The absorbance spectra were analyzed using the [14, 15] relation:

$$
h v F\left(R_{\infty}\right)=K\left(h v-E_{b g}\right)^{\mathrm{n}}
$$

where $K$ is a constant, $F\left(R_{\infty}\right)$ is equivalent to molar extinction coefficient, $E_{b g}$ is the average band gap of the material and $n$ is also a constant that depends on the type of transition. $\mathrm{CdS}$ is a direct transition material which means $n=1 / 2$. The optical band gaps of the CdS fractions were estimated from the intercept of the tangent to linear portion of the $\left[h v F\left(R_{\infty}\right)\right]^{1 / n}$ vs. $h v$ plots on the $h v$ axis. Surface areas of the samples were determined from BET measurements on a 3Flex Surface Characterization Analyzer (Micrometrics, USA).

\section{Results and Discussion}

\subsection{Characterization}

\subsubsection{Structural analysis}

In Figure 1, the diffractogram of the parent CdS sample is plotted. The result shows prominent peaks at $24.8^{\circ}, 26.5^{\circ}, 28.2^{\circ}, 43.7^{\circ}, 47.9^{\circ}$, $51.9^{\circ}, 51.9^{\circ}, 52.9^{\circ}, 54.6^{\circ}, 58.4^{\circ}, 66.9^{\circ}, 69.3^{\circ}$, $71.0^{\circ}, 72.4^{\circ}$, and $75.7^{\circ}$. These peaks are indexed to reflection from the crystalline planes (see Figure 1) of hexagonal CdS that match PDF 77-2306. The sharp and high peak intensities of the lattice reflections are indications that the sample has well grown crystals and relatively regular crystalline structure $[12,16]$.

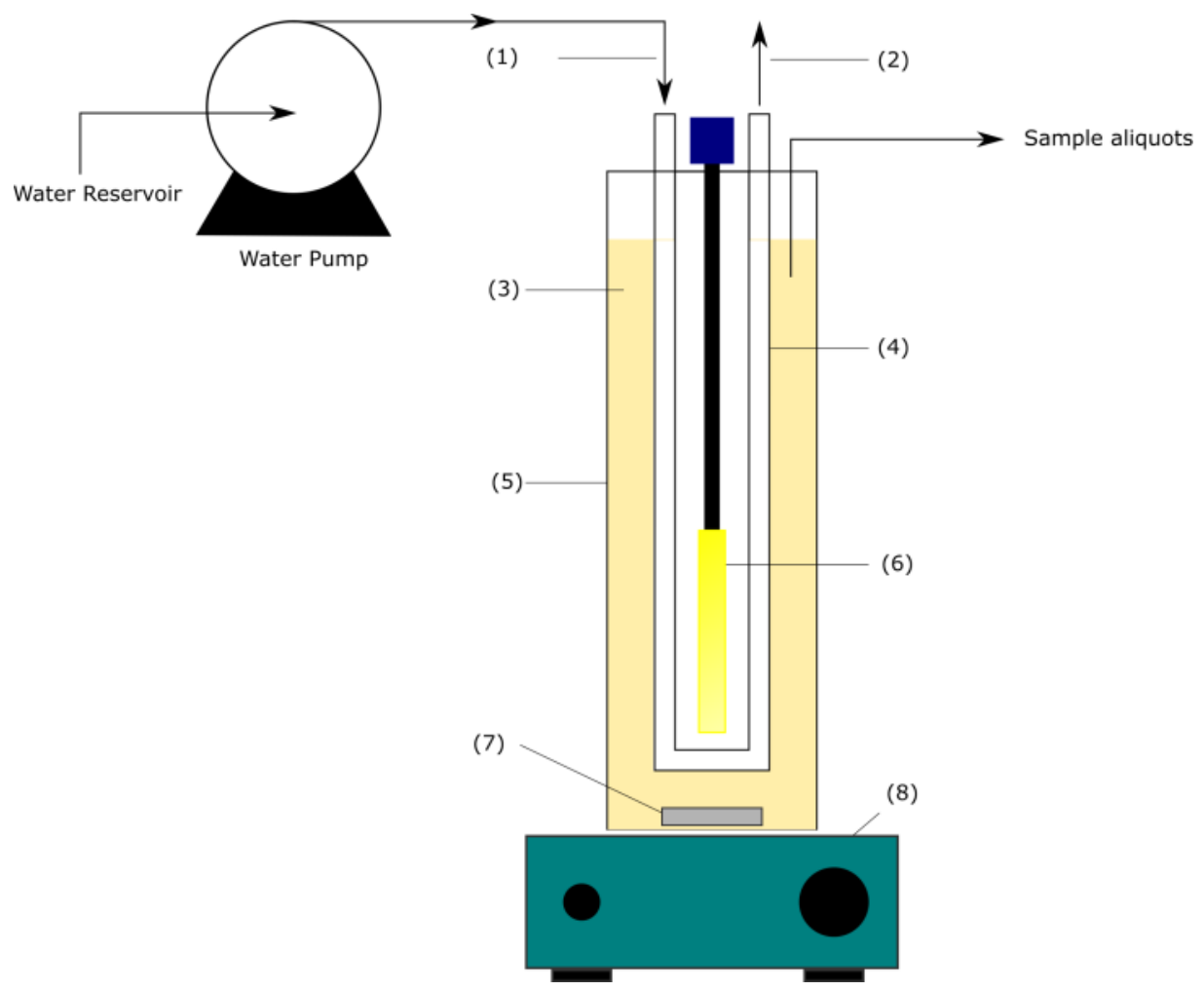

Scheme 1. Schematic diagram of the photocatalytic reduction setup. Cooling water inlet (1), cooling water outlet (2), Cr(VI) solution (3), quartz glass lamp sleeve (4), borosilicate glass photoreactor (5), visible-light source (6), magnetic bar (7), and hot plate and magnetic stirrer (8) 


\subsubsection{Morphological and textural analyses}

The morphology of the PVP-capped CdS sample was investigated with SEM. Figure 2(a) shows a typical SEM micrograph of the assynthesized CdS sample. The photograph shows spherical particles of PVP embedded CdS. The presence of PVP limits aggregation $[12,17]$ and gives the wool-like appearance that is observed in the picture. This result is consistent with other results of polymer capped nanoparticles as reported in the literature [18]. To investigate the chemical composition of $\mathrm{CdS}$ sample, the elemental analysis of samples was performed using Energy-dispersive X-ray spectroscopy. The EDX pattern (Figure 2(b)) of the $\mathrm{CdS}$ nanoparticles is shown in Table 1 . The results show that the sample contains $70.16 \mathrm{wt} . \%$ $\mathrm{Cd}$ and $19.25 \% \mathrm{~S}$ with the balance (10.59\%) being $\mathrm{C}$.

Figures 3(a) to 3(c) show the TEM micrographs of the different $\mathrm{CdS}$ fractions: CdS-5, CdS-10, and CdS-15, respectively. It is observed from Figure 3(a) that the fraction obtained at $5000 \mathrm{rpm}$ (CdS-5) consists mainly of large angular particles. On the other hand, the

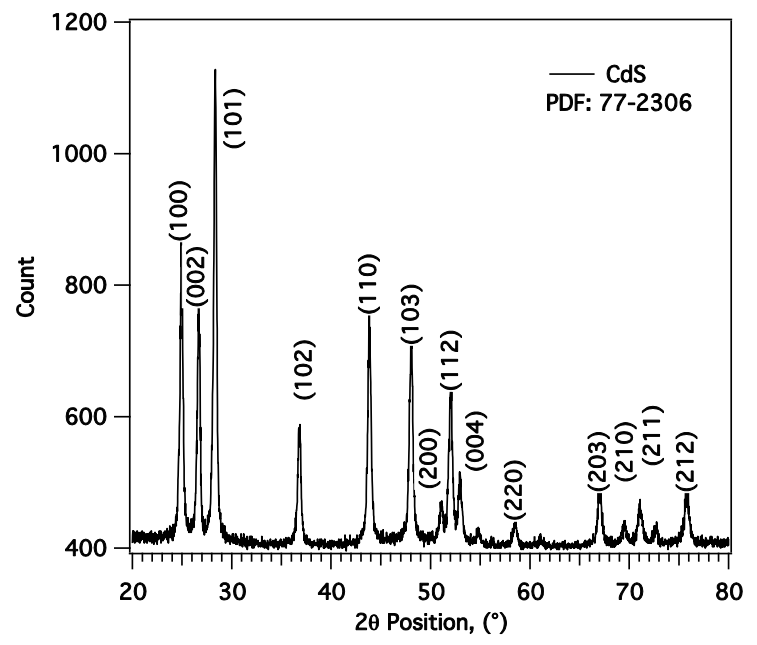

Figure 1. Diffractograms of the as-produced CdS nanoparticles collected
CdS-10 (10000 rpm; Figure 3(b)) and CdS-15 (15000 rpm; Figure 3(c)) samples consist of uniformly shaped spherical particles. The differences in morphology between the $\mathrm{CdS}-5$ and the other samples could be due to particle aggregation. The mean particles size distributions of the fractions determined by counting using the software FIJI [19] are shown in Figure $3(\mathrm{~d})$ and the computed particle diameters are listed in Table 2 . The relatively large particles (CdS-5 and CdS-10) settled out at 5000 and 10000 rpms before the settling out of the

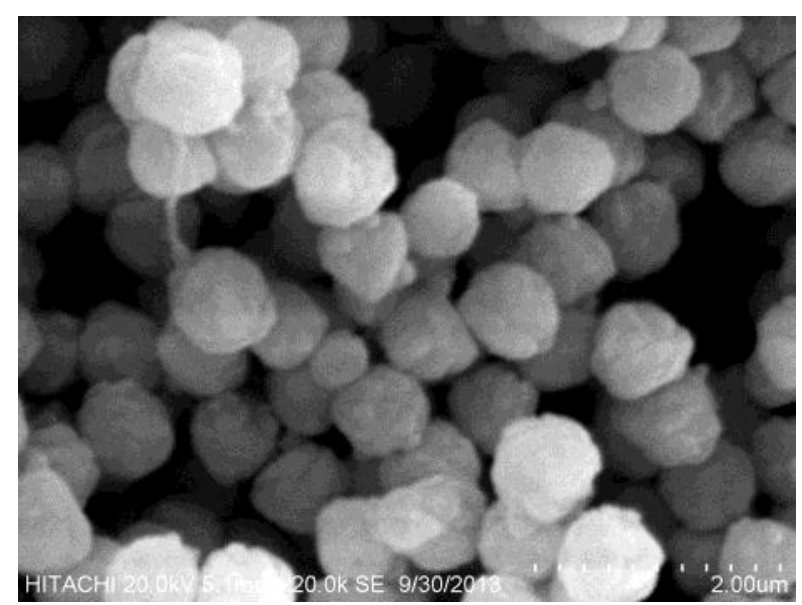

Figure 2(a). SEM micrograph

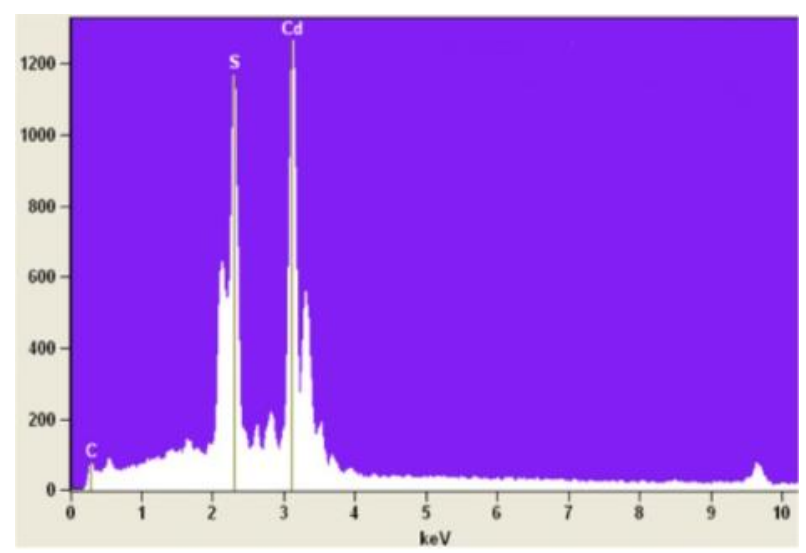

Figure 2(b). EDX spectrum of the as-produced CdS sample

Table 1. Elemental composition of as-produced CdS sample.

\begin{tabular}{cccc}
\hline Element line & Weight \% & Atom \% & Compound \\
\hline C K & 10.59 & 34.57 & 10.59 \\
S K & 19.25 & 32.13 & 19.25 \\
Cd L & 70.16 & 33.40 & 70.16 \\
\hline Total & 100.00 & 100.00 & 100.00 \\
\hline
\end{tabular}


smaller sized particle CdS-15 at $15000 \mathrm{rpm}$.

\subsubsection{UV-Visible analysis}

Figure 4 shows the room temperature diffuse reflectance spectra of the different $\mathrm{CdS}$ fractions. These spectra show the typical features of group II-VI semiconductor nanoparticles. As is evident from the figure, all the samples begin to absorb between 400 to $500 \mathrm{~nm}$. This corresponds to absorption edges less than that of bulk CdS $(\approx 515 \mathrm{~nm},[20])$ which is indicative of a blue-shift in the band gaps of the samples. The inset of Figure 4 shows the Tauc plots and the corresponding band gaps of the fractions CdS-5, CdS-10, and CdS-15 as 2.5, 2.6 and $2.9 \mathrm{eV}$ respectively. Tauc plots (inset of Figure 4) show the band gaps of the samples have blue shifted by about $0.1,0.2$ and $0.5 \mathrm{eV}$ compared to that of bulk CdS $(2.4 \mathrm{eV})$. The shifts are quantitatively consistent with the re-
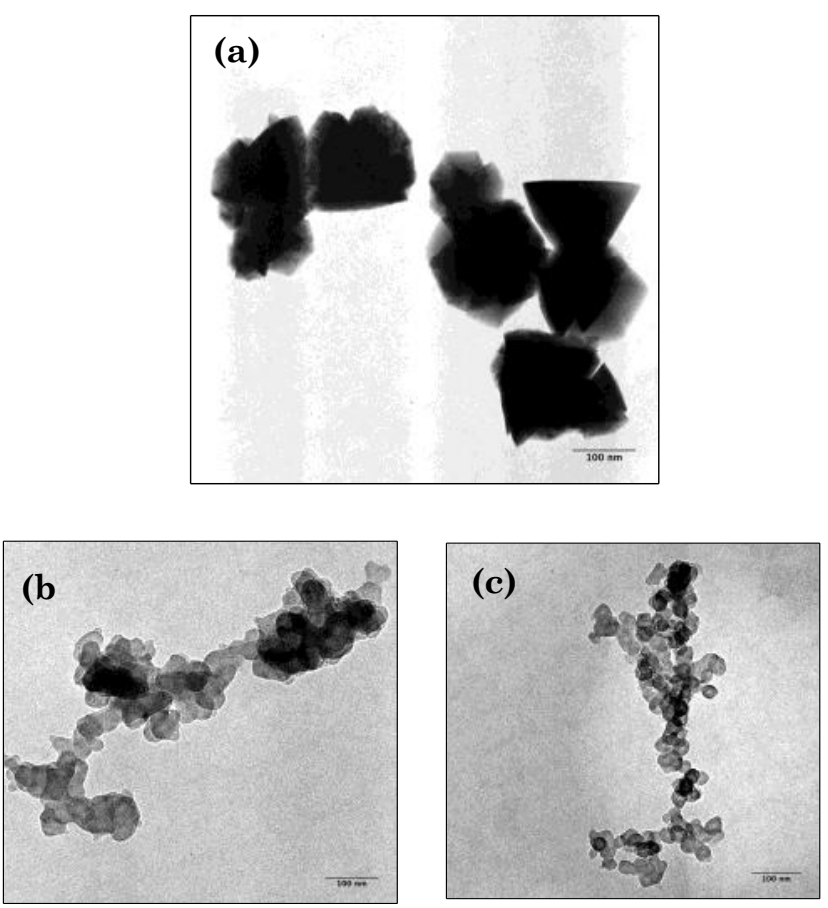

Figure 3. Micrographs of the as-produced CdS nanoparticles collected at: (a) $5000 \mathrm{rpm}$ (CdS-5), (b) $10000 \mathrm{rpm}$ (CdS-10), (c) $15000 \mathrm{rpm}$ (CdS-15) sults of previous work [16]. The increase in band gap with decrease in particle size can be attributed to size confinement effect $[17,20]$.

\subsubsection{BET analysis}

Figures 5(a) to 5(c) show the $\mathrm{N}_{2}$ adsorptiondesorption isotherms for the different CdS fractions. The profiles exhibit the typical type IV isotherm with its characteristic hysteresis indicating that the fractions are mesoporous [21]. The specific surface areas (BET) of the fractions determined are summarized in Table 2 . From the table, it is observed that the largest surface area $\left(98.7 \mathrm{~m}^{2} / \mathrm{g}\right)$ was observed for CdS15 , followed by CdS-10 $\left(79.1 \mathrm{~m}^{2} / \mathrm{g}\right)$ and then finally by CdS-5 which gave the lowest surface area of $44.2 \mathrm{~m}^{2} / \mathrm{g}$. The result showed that the specific surface area has an inverse relationship with particle size [22,23].

\subsection{Photocatalytic reduction of $\mathrm{Cr}(\mathrm{VI})$}

Figure 6 shows the temporal decay of $\mathrm{Cr}(\mathrm{VI})$ concentration over different $\mathrm{CdS}$ fractions because of adsorption (dark region) and then by photocatalysis under visible light irradiation.

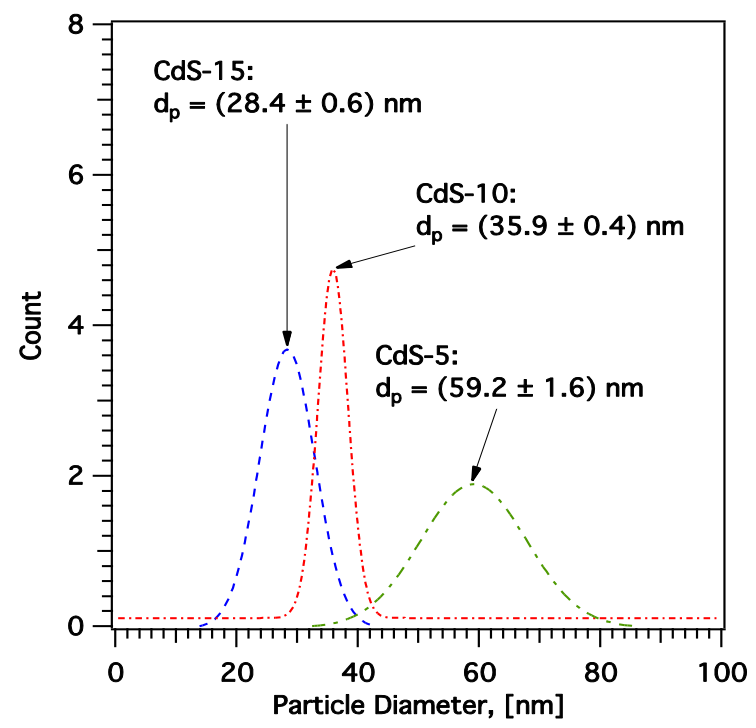

Figure 3(d). Gaussian fits of the fractions' particle size distribution.

Table 2. Some properties of the CdS fractions used in this study

\begin{tabular}{cccc}
\hline Sample Fraction & TEM Size, nm & BET, m²/g & $E g$, eV \\
\hline CdS-5 & $59.2 \pm 1.6$ & $44.2 \pm 0.6$ & 2.5 \\
CdS-10 & $35.9 \pm 0.4$ & $79.1 \pm 0.3$ & 2.6 \\
CdS-15 & $28.4 \pm 0.6$ & $98.7 \pm 0.5$ & 2.9 \\
\hline
\end{tabular}


The figure showed that irrespective of the CdS particle size, $\mathrm{Cr}(\mathrm{VI})$ was removed by all the samples. However, the removal is more efficient over CdS-15 than it was over CdS-10 and CdS-5. The concentration of $\mathrm{Cr}(\mathrm{VI})$ exponentially decreased more rapidly as the size of the catalyst decrease. For CdS-15, it is observed that about $70 \%$ of the initial $\mathrm{Cr}(\mathrm{VI})$ was reduced within the first 20 min of illumination thereafter the fall begins to flatten out. The fall in reduction rate has been attributed to decrease in $\mathrm{Cr}(\mathrm{VI})$ concentration and also to the cumulative deposition of $\mathrm{Cr}(\mathrm{OH})$ onto the surface of the photocatalyst [24]. The experimental results showed that on comparison as the surface area increased from $44.2 \pm 0.6$ to $98.7 \pm 0.5$ $\mathrm{m}^{2} / \mathrm{g}$ due to particle size reduction, the rate of $\mathrm{Cr}(\mathrm{VI})$ reduction nearly doubled in the first 20 min of visible light irradiation.

The temporal photocatalytic decay of $\mathrm{Cr}(\mathrm{VI})$ concentration has been shown to obey the pseudo-first order rate kinetics $[6,25,26]$ :

$$
C_{t}=C_{0} \exp \left(-k_{a} t\right)
$$

where $k_{a}$ is the apparent first-order rate constant, and $C_{0}$ is the initial concentration of the $\mathrm{Cr}(\mathrm{VI})$ pollutant. The rate constant, $k_{a}$, is determined by nonlinear regressing of experimental data as shown by the solid lines in Figure 6 .

The relationship between the reaction rate and particle size could be determined for the

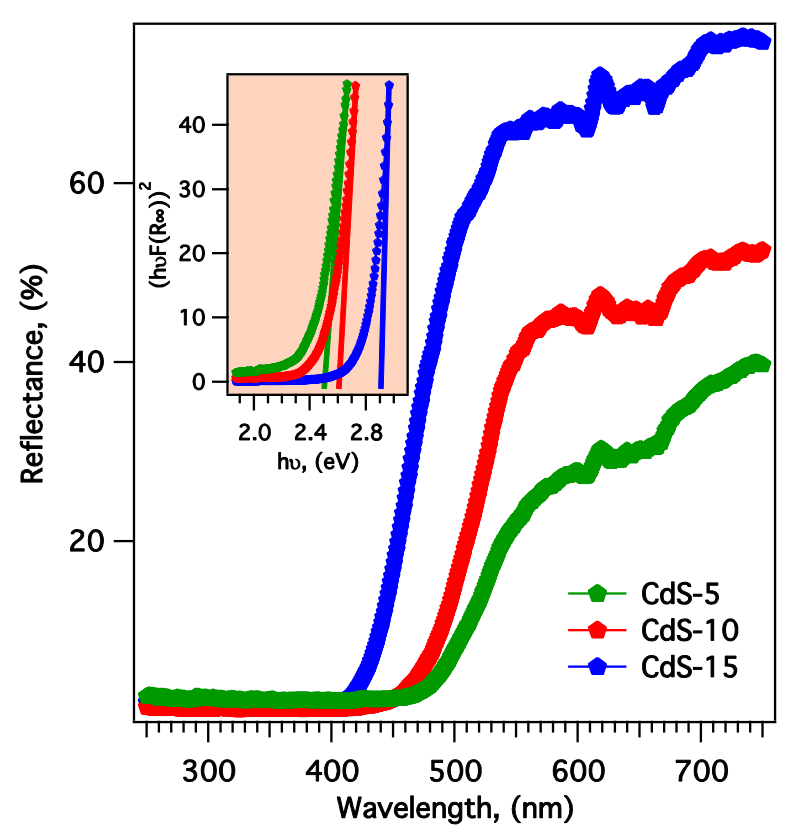

Figure 4. Room temperature diffuse reflectance spectra of the CdS fractions. Inset: $\left[h v F\left(R_{\infty}\right)\right]^{2}$ vs. $h v$ Tauc [14] plot for the determination of the band gap transition energies of the samples
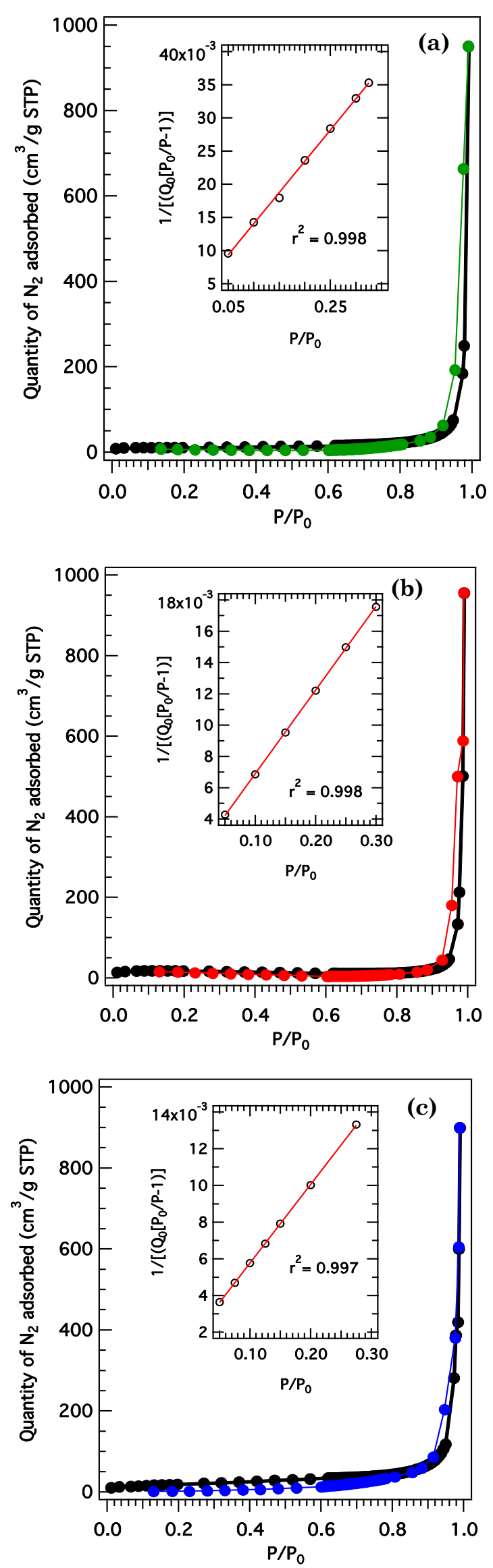

Figure 5. BET Analysis of the CdS fractions: (a) CdS-5, (b) CdS-10, (c) CdS-15 
suspended systems by examining the experimental results. Careful inspection of the profiles of the plots in Figure 6, suggests that the relationships between each of the parameters and particle diameter is logarithmic of the form presented in the previous work [27]. Accordingly, experimental data were fitted to a logarithmic function of the form:

$$
y=y_{0}+A \ln (d)
$$

where $y_{0}$ and $A$ are constants and $d(\mathrm{~nm})$ is particle diameter. The constants $\left(y_{0}\right.$ and $A$ ) that establish the respective relationship between $r_{0}$ $(\mathrm{mg} / \mathrm{L} . \mathrm{s}), k_{a}\left(\mathrm{~min}^{-1}\right)$, and $t_{1 / 2}(\mathrm{~min})$ of photoreduction of $\mathrm{Cr}(\mathrm{VI})$ and particle diameter of the CdS are obtained by non-linear fit of experimental data to Equation (3). The relationships that favorably approximates the $r_{0}, k_{a}$, and $t_{1 / 2}$ to the photocatalyst particle size are:

$$
\begin{aligned}
& k_{a}=0.163-0.033 \ln (d) \\
& r_{0}=0.258-0.055 \ln (d) \\
& t_{1 / 2}=-30.028+13.416 \ln (d)
\end{aligned}
$$

Figure 7 shows the variations of (a) reaction rate, $\left(r_{0}\right)$ with diameter, (b) rate constant, $\left(k_{a}\right)$ with diameter, and (c) half-life time $t_{1 / 2}$ with diameter, respectively. From the figure, it is observed that both initial rate and rate constant have inverse relationship with $\mathrm{CdS}$ diameter. Conversely, half-life period has direct relationship with particle size. That is, it increases (or

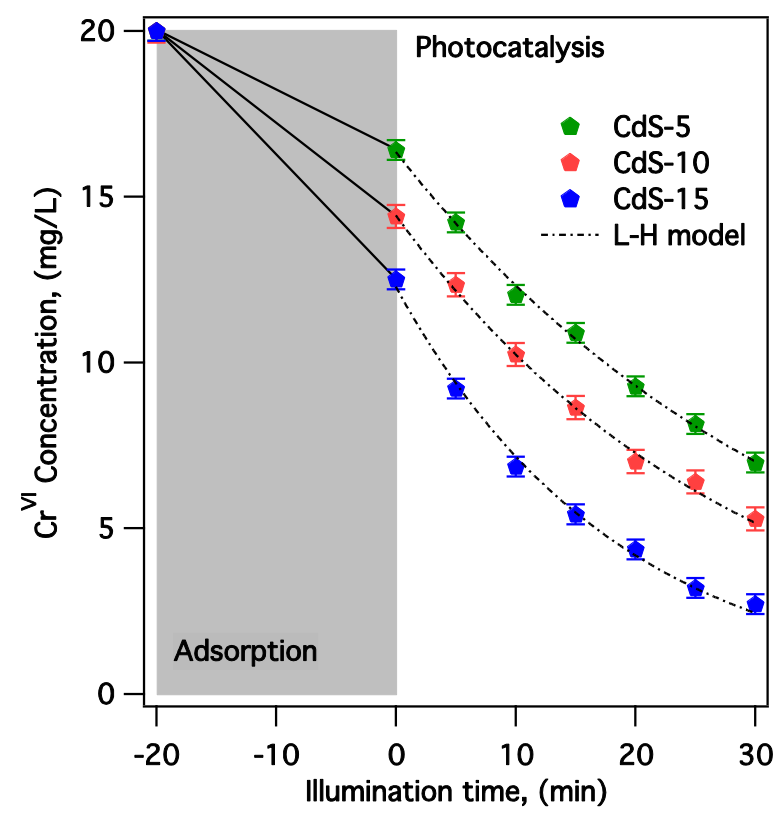

Figure 6. Decay of normalized Cr(VI) concentration using CdS powder of different particle sizes as photocatalysts. The dot-dashed lines are nonlinear fits of experimental data to Equation (1) decreases) with increase (or decrease) in particle size. This result is consistent with the finding of previous work [27] working on $\mathrm{TiO}_{2} /$ methylene blue/UV system.

\section{Conclusions}

CdS nanoparticles were prepared by microwave assisted polyol synthesis method. The reduction of $\mathrm{Cr}(\mathrm{VI})$ to $\mathrm{Cr}(\mathrm{III})$ was studied in suspended solutions of CdS photocatalyst of different particle sizes. The adsorbability of $\mathrm{Cr}(\mathrm{VI})$ on suspended CdS particles increased as the particle sizes decreased. Similarly, the photocatalytic activity also increased with the decrease in the CdS particle size. The initial reduction rate, $r_{0}$, apparent rate constant, $k_{a}$ and half-life, $t_{1 / 2}$ of photoreduction of $\mathrm{Cr}(\mathrm{VI})$ are found to be logarithmic functions of particle diameter. Both the $r_{0}$ and $k_{a}$ were found to increase with decrease in particle diameter. Whereas, the half-life times of $\mathrm{Cr}(\mathrm{VI})$ reduction increase with increase in diameter. Thus, the photocatalytic activity increased as the CdS particle size became smaller.

\section{Acknowledgement}

The authors gratefully acknowledge the financial support provided by the Ministry of Education, Government of Malaysia, through

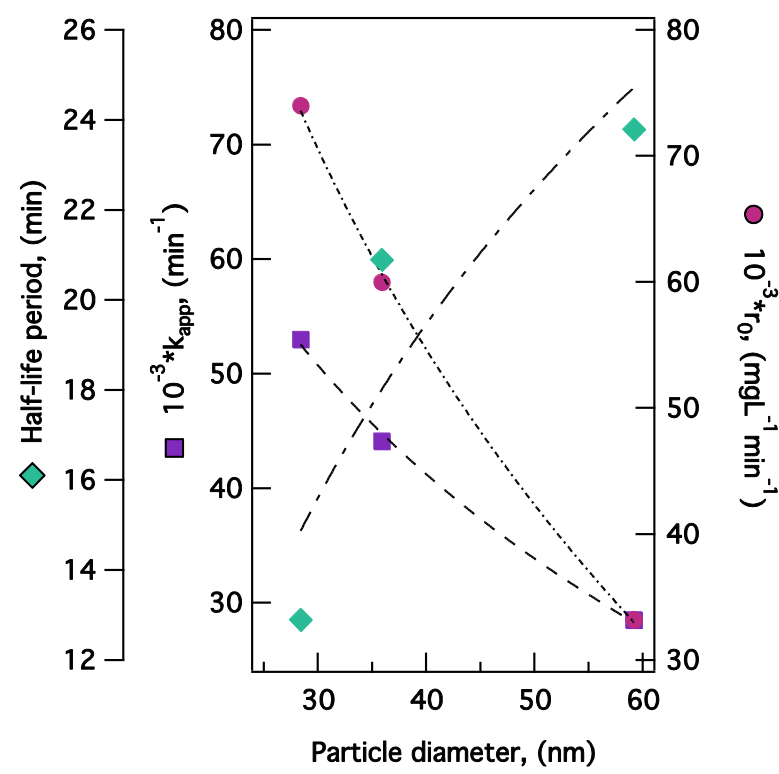

Figure 7. Variations of first-order rate constant, $k_{a}$ (filled box), initial rate, $r_{0}$ (filled circle) and half-life, $t_{1 / 2}$ (filled rhombus) with the catalyst particle diameter. The calculated data from relationship Equations 3 to 5 are plotted for comparison as the different dashed lines 
Grant no. FGRS/1/11/TK/UPM/02/34, dated 1 August 2011, and RU Project Grant no. 05-0212-2193RU.

\section{References}

[1] Chen, X., Li, C., Gratzel, M., Kosteckid, R., Mao, S.S. (2012). Nanomaterials for Renewable Energy Production and Storage. Chemical Society Review, 41: 7909-7937.

[2] Al-Fatesh, A.S.A., Fakeeha, A.H. (2012). Effects of Calcination and Activation Temperature on Dry Reforming Catalysts. Journal of Saudi Chemical Society, 16(1): 55-61.

[3] Gregor, C., Hermanek, M., Jancik, D., Pechousek, J., Filip, J., Hrbac, J. (2010). The Effect of Surface Area and Crystal Structure on the Catalytic Efficiency of Iron(III) Oxide Nanoparticles in Hydrogen Peroxide Decomposition. European Journal of Inorganic Chemistry, 16: 2343-2351.

[4] Ketir, W., Rekhila, G., Trari, M., Amrane, A. (2012). Preparation, Characterization and Application of $\mathrm{CuCrO}_{2} / \mathrm{ZnO}$ Photocatalysts for the Reduction of $\mathrm{Cr}(\mathrm{VI})$. Journal of Environmental Sciences, 24(12): 2173-2179.

[5] Yang, W., Liu, Y., Hu, Y., Zhou, M., Qian, H. (2012). Microwave-assisted Synthesis of Porous CdO-CdS Core-shell Nanoboxes with Enhanced Visible-light Driven Photocatalytic Reduction of $\mathrm{Cr}(\mathrm{VI})$. Journal of Materials Chemistry, 22: 13895-13898.

[6] Yang, J.K., Lee, S.M., Farrokhi, M., Giahi, O., Shirzad, S.M. (2012). Photocatalytic Removal of $\mathrm{Cr}(\mathrm{VI})$ with Illuminated $\mathrm{TiO}_{2}$. Desalination and Water Treatment, 46(1-3): 375-380.

[7] Zhang, Y.C., Li, J., Zhang, M., Dionysiou, D.D. (2011). Size-tunable Hydrothermal Synthesis of $\mathrm{SnS}_{2}$ Nanocrystals with High Performance in Visible Light-driven Photocatalytic Reduction of Aqueous Cr(VI). Environmental Science and Technology, 45(21): 93249331.

[8] Prairie, M.R., Evans, L.R., Stange, B.M., Martinez, S.L. (1993). An Investigation of $\mathrm{TiO}_{2}$ Photocatalysis for the Treatment of Water Contaminated with Metals and Organic Chemicals. Environmental Science and Technology, 27(9): 1776-1782.

[9] Idris, A., Hassan, N., Rashid, R., Ngomsik, A.F. (2011). Kinetic and Regeneration Studies of Photocatalytic Magnetic Separable Beads for Chromium (VI) Reduction under Sunlight. Journal of Hazardous Materials, 186(1): 629635.

[10] Munoz, J., Domenech, X. (1990). $\mathrm{TiO}_{2}$ Catalysed Reduction of $\mathrm{Cr}(\mathrm{VI})$ in Aqueous Solutions under Ultraviolet Illumination. Journal of Applied Electrochemistry, 20(3): 518-521.
[11] Alam, M., Montalvo, R. (1998). Titaniaassisted Photoreduction of $\mathrm{Cr}(\mathrm{VI})$ to $\mathrm{Cr}$ (III) in Aqueous Media: Kinetics and Mechanisms. Metallurgical and Materials Transactions B, 29(1): 95-104.

[12] Soltani, N., Saion, E., Erfani, M., Rezaee, K., Bahmanrokh, G., Drummen, G.P.C., Bahrani, A., Hussien, M.Z. (2012). Influence of the Polyvinyl Pyrrolidone Concentration on Particle Size and Dispersion of ZnS Nanoparticles Synthesized by Microwave Irradiation. International Journal of Molecular Sciences, 13(10): 12412-12427.

[13] APHA, AWWA, WEF. Eds. Rice, E.W., Baird, R.B., Eaton, A.D., Clesceri, L.S. (2012). Standard Methods for the Examination of Water and Wastewater, Washington, D.C. APHAAWWA-WEF.

[14] Tauc, J., Menth, A. (1972). States in the Gap. Journal of Non-Crystalline Solids, 8-10: 569585.

[15] Murphy, A. (2007). Band-gap Determination from Diffuse Reflectance Measurements of Semiconductor Films and Application to Photoelectrochemical Water-splitting. Solar Energy Materials and Solar Cells, 91(14): 13261337.

[16] Deng, C., Tian, X. (2013). Facile Microwaveassisted Aqueous Synthesis of CdS Nanocrystals with their Photocatalytic Activities under Visible Lighting. Materials Research Bulletin, 48(10): 4344-4350.

[17] Murphy, C.J., Coffer, J.L. (2002). Quantum dots: A Primer. Applied Spectroscopy, 56(1): 16A-27A.

[18] He, R., Qian, X-f., Yin, J., Xi, H-a., Bian, L-j., Zhu, Z-k. (2003). Formation of Monodispersed PVP-capped ZnS and CdS Nanocrystals under Microwave Irradiation. Colloids and Surfaces A: Physicochemical and Engineering Aspects, 220(1-3): 151-157.

[19] Schindelin, J., Arganda-Carreras, I., Frise, E., Kaynig, V., Longair, M., Pietzsch, T., Preibisch, S., Rueden, C., Saalfeld, S., Schmid, B., Tinevez, J.Y., White, D. J., Hartenstein, V., Eliceiri, K., Tomancak, P., Cardona, A. (2012). Fiji: An Open-source Platform for Biological-image Analysis. $\mathrm{Na}$ ture Methods, 9(7): 676--682.

[20] Henglein, A. (1989). Small-particle Research: Physicochemical Properties of Extremely Small Colloidal Metal and Semiconductor Particles. Chemical Review, 89(8): 1861-1873.

[21] Merian, E. (1982). Particle Size Measurement. Chemosphere, 11(6): N18-N19.

[22] Sing, K.S.W., Everet, D., Haul, R.A.W., Moscou, L., Pierot, R.A., Rouquerol, J., Siemieniewska, T. (1982). Reporting Phy- 
sisorption Data for Gas/solid Systems with Special Reference to the Determination of Surface Area and Porosity (recommendations 1984). Pure and Applied Chemistry, 54(11): 2201-2218.

[23] Allen, T., (1997). Particle Size Measurement, vol. 2. 5 ed.; Boundary Row, London: Chapman \& Hall.

[24] Wang, S., Wang, Z., Zhuang, Q. (1992). Photocatalytic Reduction of the Environmental Pollutant $\mathrm{Cr}(\mathrm{VI})$ over a Cadmium Sulphide Powder under Visible Light Illumination. Applied Catalysis B: Environment, 1(4): 257-270.

[25] Wu, Q., Zhao, J., Qin, G., Wang, C., Tong, X., Xue, S. (2013) Photocatalytic Reduction of Cr(VI) with $\mathrm{TiO}_{2}$ Film under Visible Light. Applied Catalysis B: Environment, 142-143: 142-148.
[26] Meichtry, J.M., Rivera, V., Di, I.Y., Rodriguez, H.B., Roman, E.S., Grela, M.A., Litter, M. I. (2009). Photoreduction of $\mathrm{Cr}(\mathrm{VI})$ using Hydroxoaluminium tricarboxymonoamide Phthalocyanine Adsorbed on $\mathrm{TiO}_{2}$. Photochemical and Photobiological Sciences, 8: 604612 .

[27] Xu, N., Shi, Z., Fan, Y., Dong, J., Shi, J., Hu, M.Z.C. (1999). Effects of Particle Size of $\mathrm{TiO}_{2}$ on Photocatalytic Degradation of Methylene Blue in Aqueous Suspensions. Industrial \& Engineering Chemistry Research, 38(2): 373379 . 